\title{
DETERMINATION OF FREQUENCY PROPERTIES OF JATROPHA CURCAS FRUITS STALK FOR MECHANICAL HARVESTING OPERATIONS
}

\author{
RAMLI M.R.H. ${ }^{1}$, HUDZARI R.M. ${ }^{1}$, WAHAB F.I.A. ${ }^{2}$, GHANI M.N.A. ${ }^{1}$ \\ 1Department of Agriculture Science, Faculty of Agriculture and Biotechnology, Universiti Sultan Zainal Abidin, Terengganu, \\ Malaysia \\ 2Department of Agrotechnology, Faculty of Agrotechnology and Food Science, Universiti Malaysia Terengganu \\ *Corresponding Author: Email - hud47@hotmail.com
}

Received: June 12, 2011; Accepted: August 22, 2011

\begin{abstract}
Jatropha curcas is a multipurpose bush or a small tree belonging to the family of Euphorbiaceae is gaining lot of importance for the production of biodiesel. It is a plant with many attributes, multiple uses and considerable potentials. It is a tropical plant that grows up to a height of $3-5$ meters and has a productive life of 50 years. It is resistant to a high degree of drought (it can be plant even in the wasteland) and as such does not compete with food crops. The seeds contain $40 \%$ oil that can be processed to produce a high-quality biodiesel fuel, usable in a standard diesel engine. Seeds are ready for harvesting around 90 days after flowering when the fruits have changed from green to yellow-brown colour. The harvesting of the Jatropha fruits is a difficult process due to the ripening characteristics of the Jatropha fruits. Harvesting machinery has been developed in order to harvest the Jatropha fruit, but the machine is not only harvest the fruit but also damaging the tree. Leaves, twigs and unripe fruits were harvested together with a low percentage of ripe fruits. To solve this problem, this study is being conducted to find the best vibration frequency for the ripe fruit to detach upon being shaken by a mechanical device without detach the unripe fruit and damaging the tree.
\end{abstract}

Key words- Jatropha curcas, cost reducing, mechanical harvesting, vibration, frequency, force and ripe fruit harvester

\section{Introduction}

Jatropha is perhaps the source for biodiesel production in the long run. Its seed is pressed for oil and the by product in the from of seed cake may be turned into organic fertilizer, while glycerine another by product have many uses. Jatropha can produce 1600 liters of oil per hectare [1]. Jatropha is inedible (except Mexico variety) and it grows in semi arid sandy land and seems to perform better in terms of seed production in those areas. It does not compete for land with other commercial plantation crops like oil palm, cocoa, rubber, tobacco and coconut. Jatropha may be the answer to the search for a viable alternative crop for replacing tobacco as shown in Malawi [2].

In Malaysia, as experienced in Europe, other sources of biofuel is expensive as they are mainly utilized for food, some example are rapeseed, peanut and sunflower seeds. Likewise, in our situation palm oil is abundant and the price do not justify for biodiesel production. The current oil price is more expensive than mineral diesel fuel, however even if palm oil is cheap, it is food and should benefit human being as food not as fuel which, if not controlled, will make the food more expensive.

Machine for harvesting of fruits have been proposed for use in Malaysia for a long time but since the structure of crop and characteristics of fruit is different for each crops, not all crops can be harvested using mechanical harvesting methods. The need to reduce labour and improve economic efficiency has stimulated efforts to mechanize the harvesting of fruit and nut crops used for processing. The high cost and slow rate of hand harvesting make mechanical harvesting desirable. A various mechanical harvesters have been introduced. Many different concepts of shakers such as trunk and limb shakers have investigated $[3 ; 4 ; 5]$.

Further research is required to produce biodiesel at a more competitive price. The present work is focused on field research for cheaper raw oil production by reducing the field cost in harvesting operation. Design the harvester robot for cocoa fruit plantation which help the farmer mechanize the agriculture operation [6] meanwhile harvesting of Jatropha is mainly done by hand. However, hand harvesting has been costly, whereby, the cost of production constitute about $80 \%$ of the total cost [7]. The objective of the study is to determine the most effective vibration characteristics (vibration frequency and amplitude) that can cause the ripe fruit to detach.

\section{Material and Methods}

The fruits on a bunch are either green, yellow or black in color. The ideal fruit for best raw oil production is yellow while the black fruits are acceptable. Green fruit is unripe and is not acceptable.

Before the data collections on work of frequency were carried out using the prototype shaker that was developed (see Figure 1), several measurements were 
taken. The measurements are diameter of the branches that will be attached to the vibration, the length of fruit stalk and the distance of fruit stalk from the main branches. The data obtained will be used in order to evaluate the frequency value that will be obtained later. The shaker will be placed on the tree limb at the fruit bunch stalk in which normally consists of unripe, ripe and overripe fruits (see Figure 2). Vibration will be imposed at the fruit bunch stalk until all the ripe fruit wholly detach. Frequency obtained that detach all the ripe fruit will be recorded using tachometer. Twelve treatments will be used in this study which involved different combinations of shaking point and amplitude that are used at the shaker. There are four positions that were used that are on the fruit stalk, $5 \mathrm{~cm}$ from stalk, $10 \mathrm{~cm}$ and $15 \mathrm{~cm}$ distance. Three different amplitudes will be used in the shaker is $2.5 \mathrm{~cm}, 3.5 \mathrm{~cm}$ and $5.5 \mathrm{~cm}$. Ten replicates were made for each treatment, see Table 1.

An experiment was conducted in a randomized complete block design (RCBD). The data obtained were subjected to analysis of variance (Statistical Analysis System) and the mean values of each treatment were compared by Duncan' $s$ multiple range test (DMRT) in order to compare the significant difference of each combination of positions and amplitudes. The experiment was carried out at National Kenaf and Tobacco Board (NKTB) research plantation, Merang, Terengganu, Malaysia.

\section{Results and Discussion}

Table 2 shows the frequency values obtained for matured fruit from the study that was conducted. Treatments using a different combination of amplitude and shaking point shows various variations on the frequency value to detach the ripe fruit (see Figure 3).

From the analysis carried out, it was found that treatment four that use amplitude $2.5 \mathrm{~cm}$ and position $15 \mathrm{~cm}$ from fruit stalk were identified as a combination which requires highest frequency value (299.0 revolution per minute (rpm)) among all twelve treatments applied. The next is treatment two and one with mean of each recording was $294.8 \mathrm{rpm}$ and $280.8 \mathrm{rpm}$. Treatment seven and five which uses $3.5 \mathrm{~cm}$ amplitude and $10 \mathrm{~cm}$ position from fruit stalk and $3.5 \mathrm{~cm}$ amplitude and position at the fruit stalk were grouped in medium value of frequency while treatment eleven $(5.5 \mathrm{~cm}$ amplitude and $10 \mathrm{~cm}$ position from fruit stalk) were identified as a most low frequency needed. Table 3 shows the mean of frequency of every treatment. From the total data collected, it was found that the frequency ranges needed to detach the ripe fruit are between $86 \mathrm{rpm}$ to $389 \mathrm{rpm}$.

Treatment four was identified as a treatment that requires the highest frequency to detach the matured fruits. The use a combination of the shortest amplitude $(2.5 \mathrm{~cm})$ and the longest of shaking point $(15 \mathrm{~cm}$ from fruit stalk) are explained why the treatment needs the high frequency. Amplitude $2.5 \mathrm{~cm}$ that are being used in combination of treatment four is the shortest amplitude compared to amplitude two $(3.5 \mathrm{~cm})$ and amplitude three $(5.5 \mathrm{~cm})$. The shorter the amplitude is used, the less the vibration generated because lack of energy from the rotation [8]. Therefore, a higher frequency is required to produce a more energetic vibration to drop the fruits. Shaking point at the tree twig are not really influenced the frequency value. Position at $15 \mathrm{~cm}$ from fruit stalk did not show a big different in the frequency required to produce a vibration that will cause fruit detach. Other than a variation of a combination of amplitude and shaking point, there are also other factors that influence the frequency value. The other factor is diameter of twig, length of fruit stalk, length of fruit from the main branches, ripening stage of fruit and position of fruit in the fruit bunch [9].

Tree twigs that have a wider diameter require a higher frequency to shake it. This is because the twig that has a wider diameter has a stronger stationary level compare to a short diameter twigs. The stronger stationary level, the higher frequencies required to move it [10].

The length of fruit stalk were also affected the frequency needed. The longer the fruit stalk, vibration in the bunch of fruit will be more powerful because the fruit bunch was shaking with a longer distance of oscillation (see Figure 4).

Distance from the main branches also affects the frequency needed. Bunch of fruit were located far from the main branches is more easily to be shaken compared with clusters of fruit which is located near with the main branch. The more easily shake the twig, the lower frequencies used.

Different stages of maturity were also a factor in this situation where it is requires a different frequency to detach the fruit of different maturity levels. The fully ripe fruit is easier to detach than fruit that is not fully matured. The last factor that affects the frequency value to detach the fruit is position of fruit in the fruit bunch. Due to Jatropha fruit is not ripe or matured at the same time, there is few level of maturity in a bunch of fruit stalk. Ripe fruit that located at the middle or slit in immature fruit require a higher vibration for detach it. This is because that fruit is flanked by other fruit and shake a little. It does not directly impact on with vibration imposed. The ripe fruit that located at the outside of fruit bunch is more easily to be detached because it is not flanked by the other fruits. A bit of vibration energy is enough to detach the fruit because the fruit was vibrating with the same vibration rate of vibration imposed and it is directly impacted.

Treatment seven $(3.5 \mathrm{~cm}$ amplitude, position $10 \mathrm{~cm})$ and treatment five $(3.5 \mathrm{~cm}$ amplitude, position at the fruit stalk) have been identified as a treatment that requiring medium (middle) of vibration frequency. It is obvious because the both treatments using a middle amplitude that has been used (amplitude two $(3.5 \mathrm{~cm})$ ) compared with the amplitude one $(2.5 \mathrm{~cm})$ of the shortest and the amplitude three $(5.5 \mathrm{~cm})$ of the longest.

Treatment had the lowest frequency is the treatment eleven which is using the combination of $5.5 \mathrm{~cm}$ amplitude and shaking point $10 \mathrm{~cm}$ from the fruit stalk. $5.5 \mathrm{~cm}$ amplitude is the longest amplitude that has been used. The use of long amplitude would produce energetic vibration even in the slow frequency. The 
longer the amplitude is used, the stronger the vibration generated [8]. Therefore, the use of longer amplitude will save more energy.

\section{Analysis of Result}

Frequency that was recorded has a significant difference at $P \leq 0.01$. Table 4 shows the analysis of variance (ANOVA) results for the frequency value for the ripe fruit. The comparison of all combination of amplitude and position of shaking point indicated that there was a significant different at $\mathrm{P} \leq 0.01$.

Mean comparison method that used in this study is Duncan' s Multiple Range Test (DMRT). Table 5 shows the treatments were classified in different groups for treatment with have a significant differences at $\mathrm{P} \leq 0.01$ between each other meanwhile the treatment with no significant difference $(P \leq 0.01)$ were classified in the same group.

\section{Conclusion}

Based on results, it is evident that the natural stage of frequency to detach the matured fruit undeniably has a different with the stage of frequency to detach the unripe fruit. The analysis indicated that range of frequencies to be used to detach the matured fruit is between 86rpm to 389rpm. Frequencies above 400rpm will detach the unripe fruits. Therefore, it is important to use the appropriate frequency to detach only the matured fruit without dropping the unripe fruit in order to avoid losses of yield.

The length of amplitude is influence the frequency value. The length of the amplitude that has been used is inversely proportional to frequency value needed. The longer amplitude used, the slower frequencies needed to detach the fruits because the longer of amplitude has more energy to shake the tree twig even in low frequency. Shaking point does not really influence the frequency used. Therefore, the vibration can be applied to any part of the appropriate branch.

Other factors that influence the frequency value namely diameter of twig, length of fruit stalk, length of fruit from the main branches, ripening stage of fruit and position of fruit in the fruit clusters should be considered to determine the frequency value that should be used.

\section{Acknowledgements}

This research will be funded by Faculty of Agriculture and Biotechnology, University Sultan Zainal Abidin. Special thanks are due to National Kenaf and Tobacco Board for their permission to use their farm for carrying out this project. Finally, the author wishes to give great thanks to Allah S.W.T which provided health and strength.

\section{References}

[1] Joachim Heller (1996) Physic nut, Jatropha curcas $L$. Promoting the conservation and use of underutilized and neglected crops. International Plant Genetic and Crop Plant
Research, Gatersleben / International Plant Genetic Resources Institute, Rome.

[2] Mkoka C. and Shanahan M. (2005) The bumpy road to clean, green fuel. Science and Development Network. http://www. scidev.net/ gateways/ index. cfm? fuseaction= readitem \&rgwid $=4 \&$ itemid $=477 \&$ language $=1$

[3] Erdogan D., Guner M., Dursun E. And Gezer I. (2003) Mechanical harvesting of apricots. Biosystems Engineering 85 (1), 19-28.

[4] Caran D. (1994) Research of possibility of mechanical harvesting of olive. Department of Agricultural Machinery. Agriculture Faculty, Ege University, Izmir, Turkey.

[5] Whitney J. D., Hartmond U., Kender W. J. and Salyani M. (2000) Applied Engineering in Agriculture, 16, 367-371.

[6] Wan Ishak Wan Ismail and Mohd Hudzari Razali (2009) Conceptual Control Design for Harvester Robot. Electronic Journal of University of Malaya. http://ejum. fsktm.um.edu.my /ArticleInformation. aspx?ArticlelD $=825$

[7] Sivapragasam A. and Mansor P. (2008) Agronomic and management practices of Jatropha cultivation in Malaysia. Malaysia Agricultural Research and Development Institute (MARDI). PowerPoint presentation of First National Workshop on Renewable Energy from Jatropha curcas, The Way Forward. August 6-7 2008. Miri, Sarawak, Malaysia.

[8] Benjamin Crowell (2010) Vibrations and Waves. Fullerton, California. http://lightandmatter.com/bk3.pdf. Accessed March 2011.

[9] Gilfillan G. (1971) Journal of Agriculture Engineering Resources.

[10] Weinrich Ulli (1984) Vibration Control of Plates, An Experimental Study Using Elastically Suspended Plate Vibration Absorbers. Master Thesis, Faculty of The College of Engineering and Technology, Ohio University. 
Table 1- Treatment was used in this study.

\begin{tabular}{|c|l|c|}
\hline Treatment No. & \multicolumn{1}{|c|}{ Combination of Treatment } & Replication \\
\hline 1 & Position 1 (at the fruit stalk), Amplitude $2.5 \mathrm{~cm}$ & \\
\hline 2 & Position 2 (5cm from stalk), Amplitude $2.5 \mathrm{~cm}$ & \multirow{2}{*}{ 10 replications } \\
\hline 3 & Position 3 (10cm from stalk), Amplitude $2.5 \mathrm{~cm}$ & \\
\hline 4 & Position 4 (15cm from stalk), Amplitude $2.5 \mathrm{~cm}$ & \\
\hline 5 & Position 1 (at the fruit stalk), Amplitude $3.5 \mathrm{~cm}$ & \\
\hline 6 & Position 2 (5cm from stalk), Amplitude $3.5 \mathrm{~cm}$ \\
\hline 7 & Position 3 (10cm from stalk), Amplitude $3.5 \mathrm{~cm}$ \\
\hline 8 & Position 4 (15cm from stalk), Amplitude $3.5 \mathrm{~cm}$ \\
\hline 9 & Position 1 (at the fruit stalk), Amplitude $5.5 \mathrm{~cm}$ \\
\hline 10 & Position 2 (5cm from stalk), Amplitude $5.5 \mathrm{~cm}$ \\
\hline 11 & Position 3 (10cm from stalk), Amplitude $5.5 \mathrm{~cm}$ \\
\hline 12 & Position 4 (15cm from stalk), Amplitude $5.5 \mathrm{~cm}$ \\
\hline
\end{tabular}

Table 2- Data of the frequency for each treatment to drop the ripe fruit

\begin{tabular}{|l|c|c|c|c|c|c|c|c|c|c|}
\hline \multirow{2}{*}{ Treatment } & \multicolumn{10}{|c|}{ Frequency (rpm) } \\
\cline { 2 - 11 } & $\begin{array}{c}\text { Rep } \\
1\end{array}$ & $\begin{array}{c}\text { Rep } \\
2\end{array}$ & $\begin{array}{c}\text { Rep } \\
3\end{array}$ & $\begin{array}{c}\text { Rep } \\
4\end{array}$ & $\begin{array}{c}\text { Rep } \\
5\end{array}$ & $\begin{array}{c}\text { Rep } \\
6\end{array}$ & $\begin{array}{c}\text { Rep } \\
7\end{array}$ & $\begin{array}{c}\text { Rep } \\
8\end{array}$ & $\begin{array}{c}\text { Rep } \\
9\end{array}$ & $\begin{array}{c}\text { Rep } \\
10\end{array}$ \\
\hline Amplitude $2.5 \mathrm{~cm}$, Position $0 \mathrm{~cm}$ & 298 & 240 & 353 & 305 & 273 & 304 & 236 & 309 & 232 & 258 \\
\hline Amplitude $2.5 \mathrm{~cm}$, Position $5 \mathrm{~cm}$ & 243 & 291 & 302 & 298 & 307 & 298 & 284 & 282 & 326 & 317 \\
\hline Amplitude $2.5 \mathrm{~cm}$, Position $10 \mathrm{~cm}$ & 198 & 157 & 230 & 203 & 221 & 270 & 240 & 230 & 130 & 270 \\
\hline Amplitude $2.5 \mathrm{~cm}$, Position $15 \mathrm{~cm}$ & 283 & 291 & 323 & 269 & 315 & 267 & 389 & 297 & 281 & 277 \\
\hline Amplitude $3.5 \mathrm{~cm}$, Position $0 \mathrm{~cm}$ & 198 & 198 & 152 & 191 & 192 & 153 & 141 & 202 & 140 & 230 \\
\hline Amplitude $3.5 \mathrm{~cm}$, Position $5 \mathrm{~cm}$ & 155 & 215 & 198 & 131 & 202 & 154 & 167 & 209 & 132 & 135 \\
\hline Amplitude $3.5 \mathrm{~cm}$, Position $10 \mathrm{~cm}$ & 194 & 202 & 158 & 199 & 211 & 183 & 203 & 160 & 201 & 217 \\
\hline Amplitude $3.5 \mathrm{~cm}$, Position $15 \mathrm{~cm}$ & 188 & 186 & 210 & 172 & 318 & 266 & 209 & 184 & 305 & 235 \\
\hline Amplitude $5.5 \mathrm{~cm}$, Position $0 \mathrm{~cm}$ & 159 & 164 & 202 & 177 & 191 & 150 & 122 & 192 & 175 & 230 \\
\hline Amplitude $5.5 \mathrm{~cm}$, Position $5 \mathrm{~cm}$ & 193 & 154 & 201 & 176 & 193 & 182 & 181 & 122 & 205 & 140 \\
\hline Amplitude $5.5 \mathrm{~cm}$, Position $10 \mathrm{~cm}$ & 178 & 86 & 132 & 182 & 165 & 192 & 186 & 169 & 124 & 186 \\
\hline Amplitude $5.5 \mathrm{~cm}$, Position $15 \mathrm{~cm}$ & 179 & 136 & 125 & 208 & 184 & 125 & 196 & 182 & 148 & 171 \\
\hline
\end{tabular}


Table 3- The means comparison of frequency of every treatment.

\begin{tabular}{|l|l|c|}
\hline \multirow{2}{*}{ No } & \multicolumn{1}{|c}{ Treatments } & Mean of frequency (rpm) \\
\cline { 3 - 3 } & & Mean $\pm($ S.E) \\
\hline 1 & T4- Amplitude 1 $(2.5 \mathrm{~cm})$, Position 4 $(15 \mathrm{~cm})$ & $299.00 \pm(11.5739)$ \\
\hline 2 & T2- Amplitude 1 $(2.5 \mathrm{~cm})$, Position 2 $(5 \mathrm{~cm})$ & $294.80 \pm(7.2000)$ \\
\hline 3 & T1- Amplitude 1 $(2.5 \mathrm{~cm})$, Position 1 $(0 \mathrm{~cm})$ & $280.80 \pm(12.4996)$ \\
\hline 4 & T8- Amplitude 2 $(3.5 \mathrm{~cm})$, Position 4 $(15 \mathrm{~cm})$ & $227.30 \pm(16.5455)$ \\
\hline 5 & T3- Amplitude 1 $(2.5 \mathrm{~cm})$, Position 3 $(10 \mathrm{~cm})$ & $214.90 \pm(14.2138)$ \\
\hline 6 & T7- Amplitude 2 $(3.5 \mathrm{~cm})$, Position 3 $(10 \mathrm{~cm})$ & $192.80 \pm(6.3207)$ \\
\hline 7 & T5- Amplitude 2 $(3.5 \mathrm{~cm})$, Position 1 $(0 \mathrm{~cm})$ & $179.70 \pm(9.7354)$ \\
\hline 8 & T9- Amplitude 3 $(5.5 \mathrm{~cm})$, Position 1 $(0 \mathrm{~cm})$ & $176.20 \pm(9.4865)$ \\
\hline 9 & T10- Amplitude 3 $(5.5 \mathrm{~cm})$, Position 2 $(5 \mathrm{~cm})$ & $174.70 \pm(8.6821)$ \\
\hline 10 & T6- Amplitude 2 $(3.5 \mathrm{~cm})$, Position 2 $(5 \mathrm{~cm})$ & $169.80 \pm(10.5586)$ \\
\hline 11 & T12- Amplitude 3 $(5.5 \mathrm{~cm})$, Position 4 $(15 \mathrm{~cm})$ & $169.70 \pm(9.4401)$ \\
\hline 12 & T11- Amplitude 3 $(5.5 \mathrm{~cm})$, Position 3 $(10 \mathrm{~cm})$ & $160.00 \pm(10.9777)$ \\
\hline
\end{tabular}

Table 4- ANOVA analysis for frequency

\begin{tabular}{|c|c|c|c|c|c|}
\hline Source & $\mathrm{DF}$ & $\begin{array}{l}\text { Sum of } \\
\text { Squares }\end{array}$ & $\begin{array}{l}\text { Mean } \\
\text { Square }\end{array}$ & F Value & $\mathrm{Pr}>\mathrm{F}$ \\
\hline Treatment & 11 & 301358.8 & 27396.25 & $23.12^{*}$ & 0.0001 \\
\hline Rep & 9 & 12226.53 & 1358.504 & 1.15 n.s & 0.3378 \\
\hline Error & 99 & 117287.1 & 1184.718 & & \\
\hline Total & 119 & 430872.4 & & & \\
\hline
\end{tabular}

Table 5- Duncan's grouping of frequency among treatments that have been used.

\begin{tabular}{|c|c|}
\hline $\begin{array}{l}\text { Duncan } \\
\text { Grouping }\end{array}$ & Treatment \\
\hline$a$ & $\begin{array}{ll}\text { 1. } & \text { Treatment } 1 \text { [Amplitude } 1(2.5 \mathrm{~cm}) \text {, Position } 1(0 \mathrm{~cm})] \\
\text { 2. } & \text { Treatment } 2 \text { [Amplitude } 1(2.5 \mathrm{~cm}) \text {, Position } 2(5 \mathrm{~cm})] \\
\text { 3. } & \text { Treatment } 4 \text { [Amplitude } 1(2.5 \mathrm{~cm}) \text {, Position } 4(15 \mathrm{~cm})]\end{array}$ \\
\hline$b$ & $\begin{array}{ll}\text { 1. } & \text { Treatment } 3 \text { [Amplitude } 1(2.5 \mathrm{~cm}) \text {, Position } 3(10 \mathrm{~cm})] \\
\text { 2. } & \text { Treatment } 8 \text { [Amplitude } 2(3.5 \mathrm{~cm}) \text {, Position } 4(15 \mathrm{~cm})]\end{array}$ \\
\hline C & $\begin{array}{ll}\text { 1. } & \text { Treatment } 3 \text { [Amplitude } 1(2.5 \mathrm{~cm}), \text { Position } 3(10 \mathrm{~cm})] \\
\text { 2. } & \text { Treatment } 7 \text { [Amplitude } 2(3.5 \mathrm{~cm}) \text {, Position } 3(10 \mathrm{~cm})]\end{array}$ \\
\hline$d$ & $\begin{array}{ll}\text { 1. } & \text { Treatment } 5 \text { [Amplitude } 2(3.5 \mathrm{~cm}) \text {, Position } 1(0 \mathrm{~cm})] \\
\text { 2. } & \text { Treatment } 6 \text { [Amplitude } 2(3.5 \mathrm{~cm}) \text {, Position } 2(5 \mathrm{~cm})] \\
\text { 3. } & \text { Treatment } 7 \text { [Amplitude } 2(3.5 \mathrm{~cm}) \text {, Position } 3(10 \mathrm{~cm})] \\
\text { 4. } & \text { Treatment } 9 \text { [Amplitude } 3(5.5 \mathrm{~cm}) \text {, Position } 1(0 \mathrm{~cm})] \\
\text { 5. } & \text { Treatment } 10 \text { [Amplitude } 3(5.5 \mathrm{~cm}) \text {, Position } 2(5 \mathrm{~cm})] \\
\text { 6. } & \text { Treatment } 11 \text { [Amplitude } 3(5.5 \mathrm{~cm}) \text {, Position } 3(10 \mathrm{~cm})] \\
\text { 7. } & \text { Treatment } 12 \text { [Amplitude } 3(5.5 \mathrm{~cm}) \text {, Position } 4(15 \mathrm{~cm})]\end{array}$ \\
\hline
\end{tabular}

${ }^{\star}$ Treatments followed by same group are not significantly different $(\mathrm{P} \leq 0.01)$. 

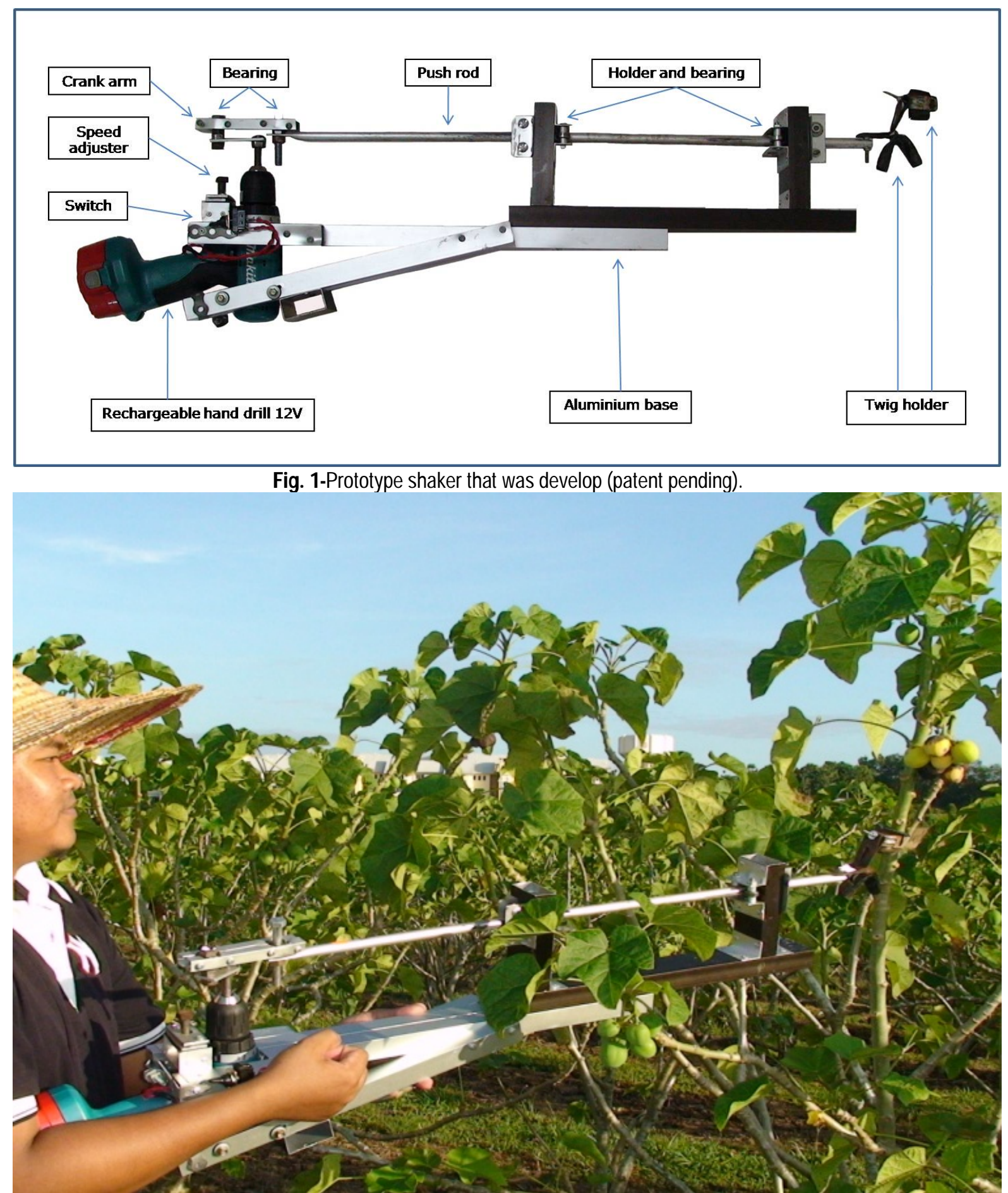

Fig. 2-The prototype shaker was attached on the tree twig for shaking. 


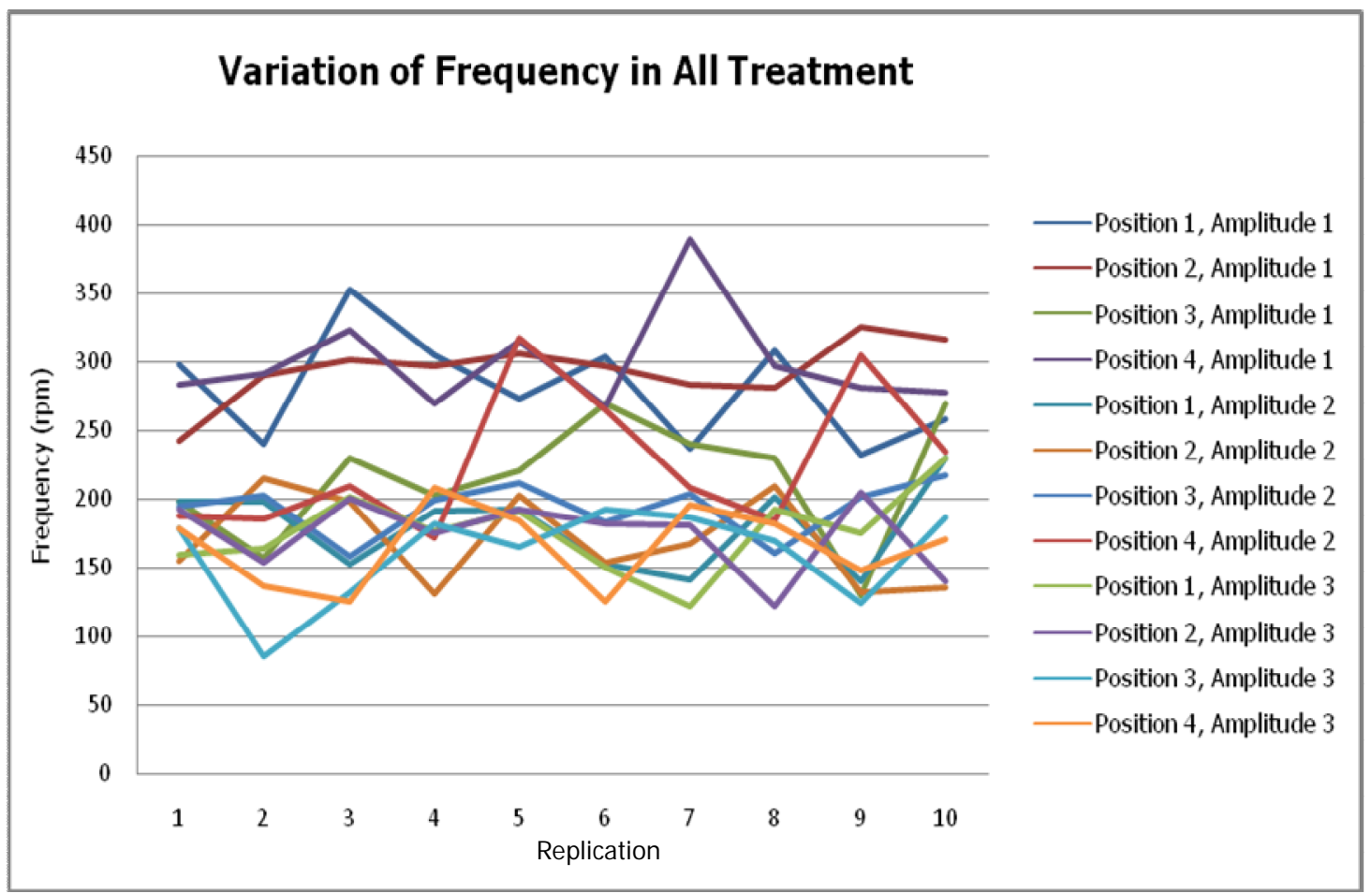

Fig. 3-Variation of frequency in all treatments
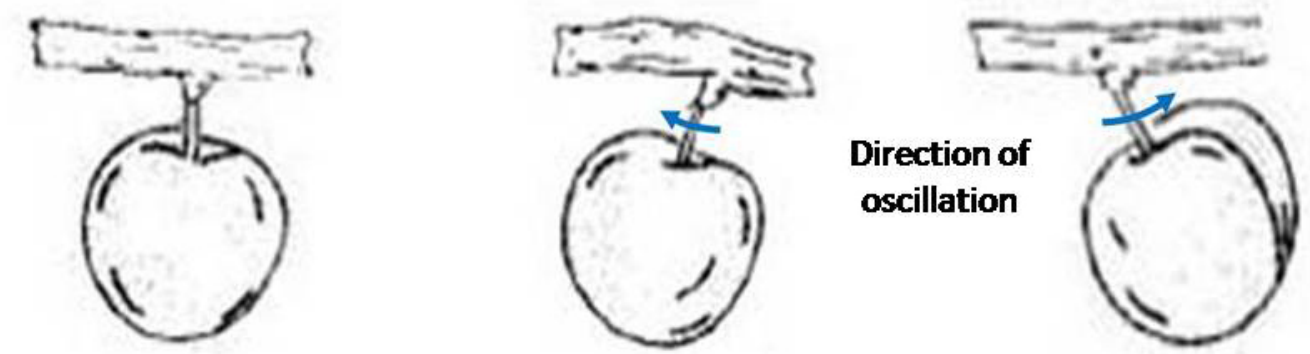

Fruit with shorter fruit stalk
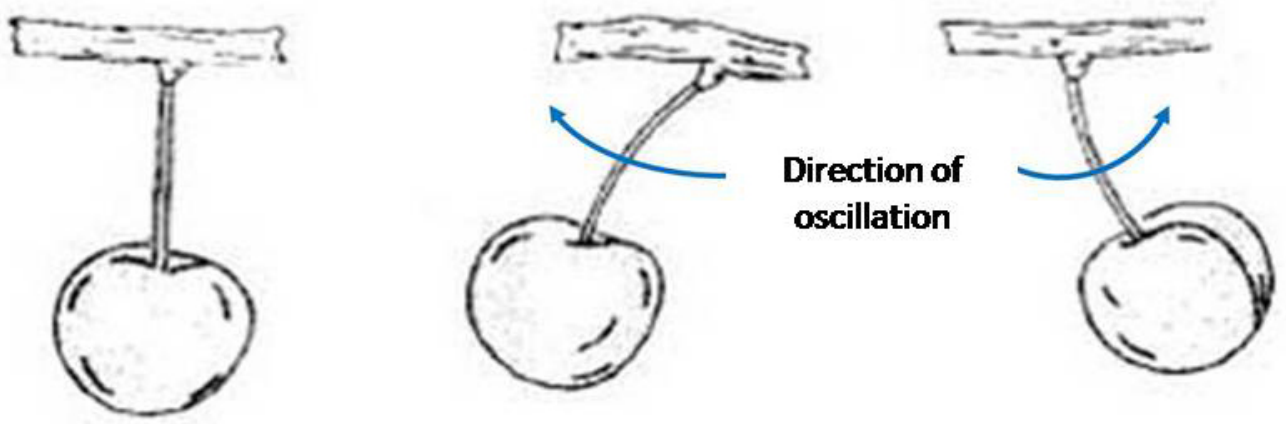

Fruit with longer fruit stalk

Fig. 4-Differences in the power of oscillation on the fruit that has a different stem length. 